Vol 14, Issue 7, 2021

\title{
DRUG PRESCRIBING PATTERN AND COST-EFFECTIVENESS ANALYSIS OF ORAL ANTIDIABETIC DRUGS IN PATIENTS WITH TYPE-2 DIABETES MELLITUS: REAL-WORLD DATA FROM INDIAN POPULATION.
}

\author{
GHADAH SALIM MUSSTTAF ${ }^{1}$, ANWAR HABIB ${ }^{2}$, MARWAN MAHTOOK ${ }^{1 *}$
}

${ }^{1}$ Department of Pharmacology, School of Pharmaceutical Education and Research, Jamia Hamdard, New Delhi, India. ${ }^{2}$ Department of Medicine, Hamdard Institute of Medical Sciences and Research, Jamia Hamdard, New Delhi, India. Email: ph.marwansaedi@gmail.com

Received: 05 April 2021, Revised and Accepted: 14 May 2021

\section{ABSTRACT}

Objectives: The objective of the study was to evaluate the drug prescribing pattern and pharmacoeconomics of oral diabetic medications in patients of type 2 diabetes mellitus visiting the medicine OPD of HAH Centenary Hospital, Jamia Hamdard, New Delhi.

Methods: Observational study conducts on 100 T2DM patients to assess their demographics and individual details such as disease history, BMI, and economic status along with the drug utilization assessment and cost-effectiveness analysis of prescribed drugs.

Results: Among 100 patients, 40 (40\%) were male, and $60(60 \%)$ were female, indicating that T2DM is slightly more prevalent in females. The mean age of the subjects included in the study is 51.46 years. Of the total number of patients, 64 were under oral antidiabetic drugs, and remaining were pregnant females under insulin. The majority of the subjects, $69.4 \%$, were on multiple drug therapy and remaining treated with monotherapy. Metformin $500 \mathrm{mg}$ (32.81\%) was the most prescribed oral antidiabetic drug followed by glimepiride 4 mg (15.62\%) and 12.5\% for glimepiride $2 \mathrm{mg}+$ metformin $500 \mathrm{mg}$, sitagliptin + metformin 50/500, and vildagliptin 50 + metformin 850, respectively. The maximum mean reduction of FBG was seen with glimepiride $4 \mathrm{mg}$ ( $34.69 \mathrm{mg} / \mathrm{dl}$ ) and lowest with metformin $500 \mathrm{mg}$ (24.05 mg/dl). The cost per unit (1 mg/dl) reduction in FBG (ACER) was highest with sitagliptin $50 \mathrm{mg}$ (INR 63.14) and lowest with glimepiride $1 \mathrm{mg}+$ metformin $500 \mathrm{mg}$ (INR 9.95).

Conclusion: Most type 2 diabetic patients in this setting were treated with multiple oral antidiabetic therapies. Metformin and sitagliptin were the most common choice as monotherapy agents. CEA concludes that the cost associated with diabetes is enormous and varies greatly. The combination therapy of glimepiride $2 \mathrm{mg}+$ metformin $500 \mathrm{mg}$ was the most cost effective.

Keywords: Diabetic control, Drug utilization, Pharmacoeconomics, Oral antidiabetic drug, Prescribing trends.

(C) 2021 The Authors. Published by Innovare Academic Sciences Pvt Ltd. This is an open access article under the CC BY license (http://creativecommons.org/ licenses/by/4.0/) DOI: http://dx.doi.org/10.22159/ajpcr.2021v14i7.41677. Journal homepage: https://innovareacademics.in/journals/index.php/ajpcr

\section{INTRODUCTION}

Around the globule, an estimated 462 million individuals are affected by type 2 diabetes, corresponding to $6.28 \%$ of the world's population. Above 1 million deaths were attributed to this condition in 2017 alone, ranking it as the ninth leading cause of mortality [1]. Drug therapy, when planed metabolic control, depends on adherence to both nonpharmacological and pharmacological treatment. Tight blood glucose level control can be correct with a reduction in diabetic complications. Commitment to prescribed medicine is crucial to achieving this control. Drug utilization studies identify treatment adherence problems or reasons for non-adherence, that is, whether inadequate control is due to missing doses or inadequate prescription [2]. Thus, drug utilization studies design interventions to improve drug use and provide physicians with feedback on their performance. Without knowing how antidiabetic drugs are being prescribed and used, it is challenging to discuss rational drug use and suggest measures to change prescribing habits for better glycemic control. Ensure prescribing instructions state the appropriate times for taking medication, and patients should be aware. Clinical judgment must be achieved when prescribing the antidiabetic drug for high-risk patients, that is, frail, women of childbearing age, renal impairment, hepatic impairment, patients unable to self-care, and patients with existing cardiovascular disease [3]. In a developing country like India, $85 \%$ of total health expenditures are financed by household pocket expenditure [4]. Many poor people frequently choose between buying medicines or buying food or other necessities due to limited resources and drugs' high pricing. The cost-effective analysis of the oral hypoglycemic agents will reduce the healthcare burden on patients with diabetes mellitus and reduce the country's total health expenditure [5]. Lack of proper knowledge of the cost of various antidiabetic drugs is regulated. A less regulated market leads to difficulties in prescribing the most cost-effective medication to the patient [6]. Hence, this study aimed to carry out a pharmacoeconomic analysis of different oral antidiabetic drugs. A trial of stopping a medicine, with careful monitoring, should be considered when there are doubts regarding the patient's continuing benefit. Therefore, this study was carried out to find the current prescribing pattern of oral antidiabetic drugs and the efficacy of these drugs in maintaining optimal glycemic control in diabetic patients visiting medicine OPD of HAH Centenary Hospital, Jamia Hamdard, New Delhi, India.

\section{METHODS}

The study is prospective observational to assess drug utilization and cost-effectiveness of oral antidiabetic medications. The study population was 100 patients who were diagnosed with type-2 diabetes mellitus and exclude those that are not confirmed with type 2 diabetes and mentally challenged or unconscious patients. The study was carried out only after the approval of the Research Project Advisory Committee (RPAC) of Hakeem Abdul Hameed Centenary Hospital (HAHC) and the Institutional Ethics Committee (IEC) of Jamia Hamdard from November 2019 to May 2020. Patients were explained about precautions and measures taken during the COVID-19 crisis. Informed consent was obtained before the participation of the subject in the study. All subject's demographics were assessed, including (disease and family history, BMI, and economic status) through developed questionnaires. All enrolled subjects who met the inclusion criteria were evaluated 
for their prescribing patterns by medication utilization form, glycated hemoglobin, FBG, and postprandial glucose levels. Comparison of the prescribed medication was performed to assess multitherapy versus monotherapy in the management of T2DM of the enrolled subjects. For pharmacoeconomic evaluation, the cost-effectiveness analysis method was used. The health-care cost of antidiabetic therapies prescribed for T2DM causing a reduction in fasting blood glucose (FBG) levels by $1 \mathrm{mg} / \mathrm{dl}$ was considered. The health-care costs included direct medical expenses, including the cost of antidiabetic drugs, physician charges, and laboratory charges. Drugs other than antidiabetic agents were not included in cost-effectiveness analysis. For the change in FBG levels, the patients were followed for 8 weeks, and the levels of FBS were recorded at baseline and after 8 weeks. Results of cost-effectiveness analysis were calculated as:

Average cost-effectiveness ratio $($ ACER $)=$ (Health-care cost during 8 weeks of therapy)/(Mean reduction in FBG levels over 8 weeks)

The cost variations of different antidiabetic therapies in terms of ACER were then compared. All antidiabetic drugs and their drug classes were recorded. The data were tabulated as mean \pm standard deviation. Results for drug utilization patterns were analyzed in terms of percentage using Microsoft Excel software. For pharmacoeconomic analysis, results were analyzed using ANOVA (one way), using GraphPad InStat software version 3.0. $\mathrm{p}<0.05$ was considered statistically significant.

\section{RESULTS}

Among the 100 type two diabetic patients, $40 \%$ were male and $60 \%$ were female indicating that type 2 diabetes mellitus is slightly more prevalent in the female gender. A total of $60 \%$ of type 2 diabetes female patients were found with gestational diabetes. The mean age of the participant subjects was found to be 51.46 years. The

Table 1: Classification of study population based on BMI

\begin{tabular}{llllll}
\hline BMI $\left(\mathbf{k g} / \mathbf{m}^{2}\right)$ & Status & Male & Female & Total & \% of patients \\
\hline$<18.5$ & Underweight & 1 & 3 & 5 & 5 \\
$18.5-22.9$ & Normal range & 12 & 15 & 27 & 27 \\
$23-24.9$ & Overweight & 10 & 12 & 22 & 22 \\
$25-29.9$ & Pre-obese & 12 & 17 & 30 & 30 \\
$\geq 30$ & Obese & 3 & 12 & 16 & 16 \\
\hline
\end{tabular}

maximum number of type 2 diabetic patients fell under the age group of 51-60 years, followed by $41-50,61-70$, and $31-40$ years in male and female subjects. The maximum number of male type 2 diabetic patients belonged to the age group of 51-60 years, and female patients were also the highest in the age group of 51-60 years. History of diabetes in enrolled patients was showing that $51 \%$ of type 2 diabetic patients were having a history of diabetes for $2-5$ years, followed by $13 \%$ for 5-10 years, 9\% within 6 months, while $11 \%$ for 6 months- 1 year, and $9 \%$ for $11-15$ years. New cases were only $6 \%$ (Fig. 1). The mean body mass index (BMI) of the participant subjects was $25.58 \mathrm{~kg} / \mathrm{m}^{2}$, slightly higher than the acceptable limits (i.e. $\leq 25 \mathrm{~kg} / \mathrm{m}^{2}$ ). A total of 30 patients $(30 \%)$ had a body mass index higher than $>25 \mathrm{~kg} / \mathrm{m}^{2}$. Of the 100 type 2 diabetic patients, 16 patients (12 females) had a body mass index of $>30 \mathrm{~kg} / \mathrm{m}^{2}$ (Table 1). A total of $30 \%$ of patients had a family history of diabetes. Male patients had more cases of family history than females. The enrolled subjects' economic status determination indicates that middle-class people have more compliance with T2DM patients. Among 100 patients, 64 patients under oral antidiabetic drugs, and the remaining were pregnant females under insulin. Metformin $500 \mathrm{mg}$ $(32.81 \%)$ was the most commonly prescribed oral antidiabetic drug followed by glimepiride $4 \mathrm{mg}(15.62 \%)$ and $12.5 \%$ for glimepiride $2 \mathrm{mg}+$ metformin $500 \mathrm{mg}$, sitagliptin $50 \mathrm{mg}+$ metformin $500 \mathrm{mg}$, and vildagliptin $50 \mathrm{mg}$ + metformin $850 \mathrm{mg}$, respectively (Table 2), (Fig. 2). A total of $35(40.62 \%)$ patients received monotherapy. The majority of the subjects $(69.4 \%)$ were on multiple drug therapy (Table 3). The fasting blood glucose (FBG) data were not available for 22 patients. Of the 86 patients for whom the data were available during the study period, $58.2 \%$ of the patients showed FBG levels higher than the acceptable limits, as shown in Table 4. Postprandial (PP) blood glucose levels were available for 74 of the total patients, $66.2 \%$ of whom had PP blood glucose levels higher than the normal limits (Table 4). The glycated hemoglobin data were available only for 45 patients. Only $57.7 \%$ of patients showed HbA1c levels within acceptable limits. For the cost-effectiveness analysis, the maximum mean reduction of FBG was seen with glimepiride $4 \mathrm{mg}(34.69 \mathrm{mg} / \mathrm{dl})$ and lowest with metformin $500 \mathrm{mg}(24.05 \mathrm{mg} / \mathrm{dl})$. The cost per unit $(1 \mathrm{mg} / \mathrm{dl})$ reduction in FBG (ACER) was highest with sitagliptin $50 \mathrm{mg}$ (INR 63.14) and lowest with glimepiride $1 \mathrm{mg}+$ metformin $500 \mathrm{mg}$ (INR 9.95) (Table 5). The maximum expenditure was on antidiabetic agents (86.63\%), followed by laboratory charges $(7.13 \%)$, and physician charges accounted for (6.24\%) of the average total direct cost.

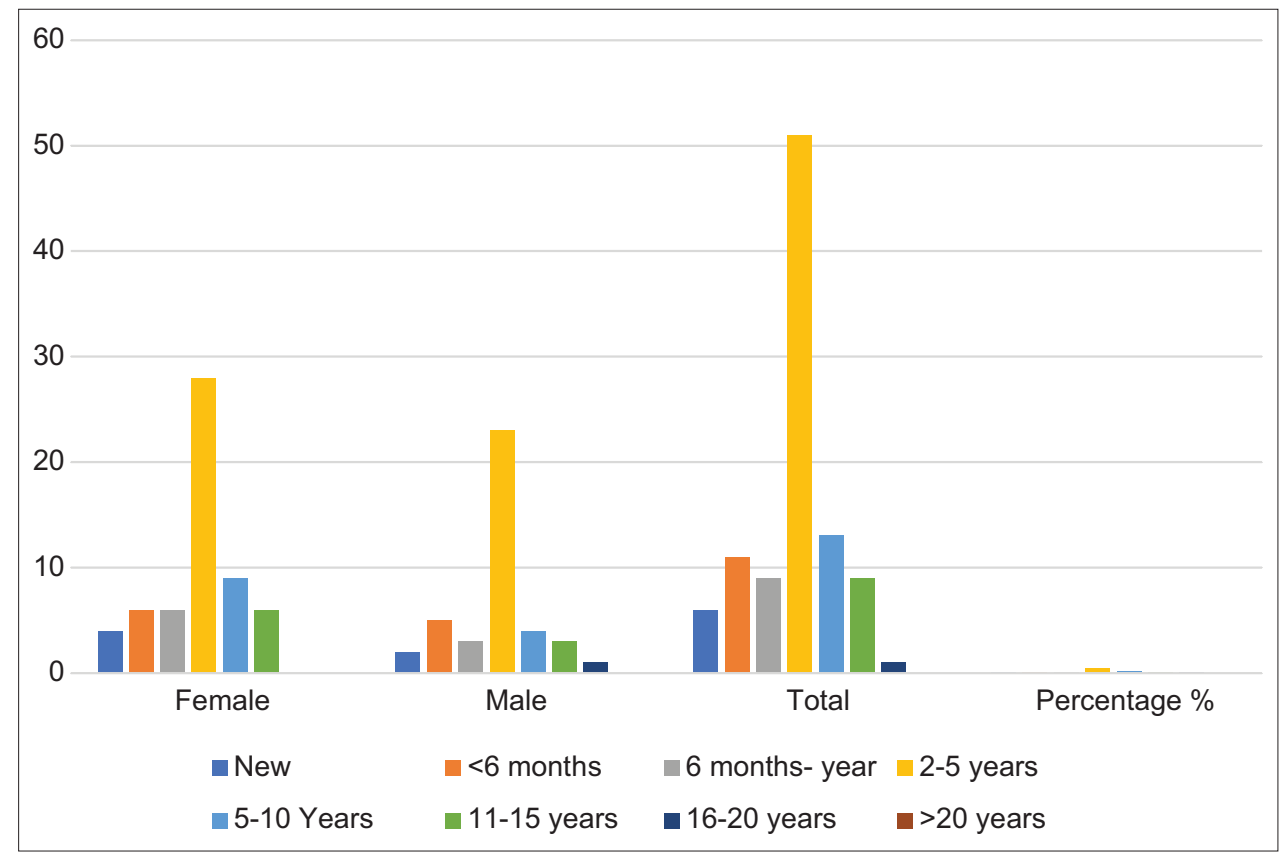

Fig. 1: History of diabetes 


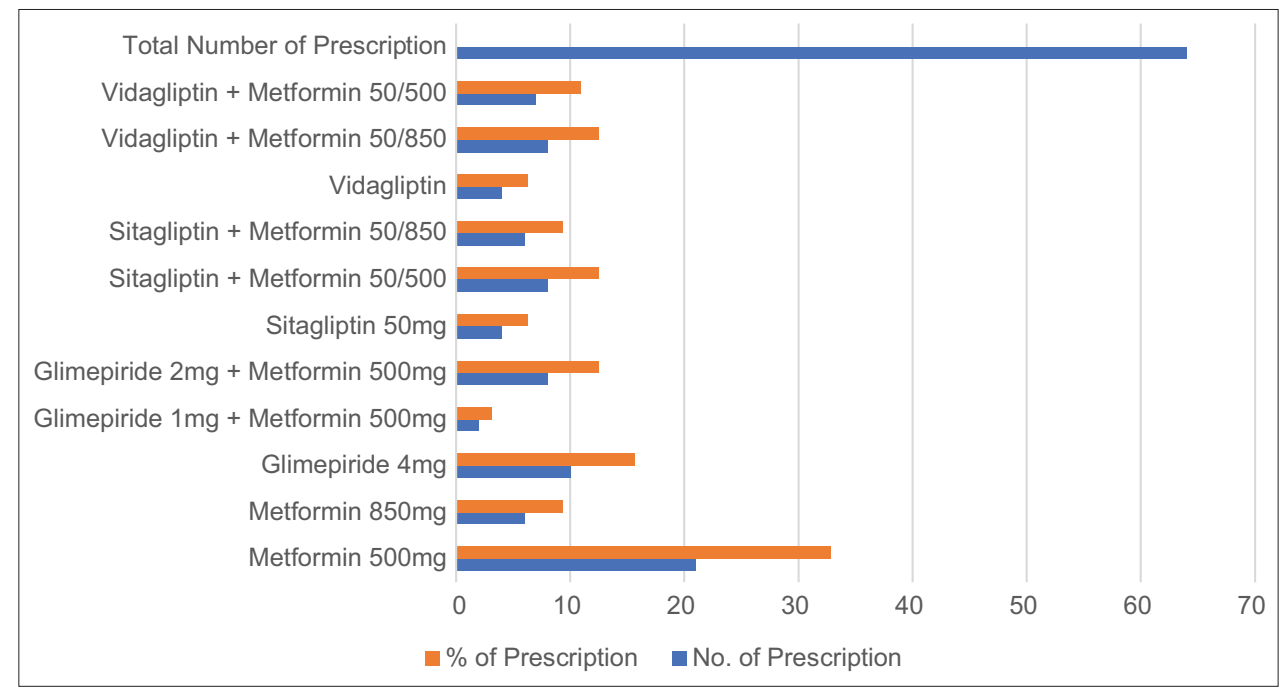

Fig. 2: Prescription patterns

Table 2: Prescribing patterns of the oral antidiabetic drug

\begin{tabular}{llll}
\hline Generic name & Brand name & No. of prescription & \% of prescription \\
\hline Metformin $500 \mathrm{mg}$ & Glucophage 500 & 21 & 32.81 \\
Metformin $850 \mathrm{mg}$ & Glucophage 850 & 6 & 9.37 \\
Glimepiride 4 mg & Amaryl 4 & 10 & 15.62 \\
Glimepiride $1 \mathrm{mg}+$ Metformin $500 \mathrm{mg}$ & GEMER 1 & 2 & 3.12 \\
Glimepiride 2 mg+Metformin 500 mg & Amaryl M & 8 & 12.5 \\
Sitagliptin 50 mg & Januvia & 4 & 6.25 \\
Sitagliptin Metformin 50/500 & Janumet 50/850 & 8 & 12.5 \\
Sitagliptin+Metformin 50/850 & Janumet 85/500 & 6.37 \\
Vildagliptin & Galvus & 4 & 6.25 \\
Vidagliptin+Metformin 50/850 & Galvus Met 50/850 & 8 & 12.5 \\
Vidagliptin+Metformin 50/500 & Galvus Met 50/500 & 7 & 10.93 \\
Total number of prescription & & 64 & \\
\hline
\end{tabular}

Table 3: Single drug therapy versus multiple drug therapy

\begin{tabular}{lll}
\hline Drug therapy prescribed & No. of patients & \% of prescription \\
\hline Single drug therapy & 26 & 40.62 \\
Multidrug therapy & & \\
Two-drug therapy & 22 & 34.375 \\
Three-drug therapy & 11 & 17.187 \\
Four-drug therapy & 5 & 7.812 \\
Total & 64 & 100 \\
Grand total & 100 & 100 \\
\hline
\end{tabular}

\section{DISCUSSION}

The current study aimed to analyze the prescription pattern and costeffectiveness of diabetic patients with or without comorbidity with a specific objective to determine the current trend of oral antidiabetic drugs in type 2 diabetes patients. According to the report obtained from the study, female patients are more prone to diabetes mellitus than males, which is similar to that reported in other Indian studies [7]. The mean age of the patients included in the study was 51.46 years and was more frequent in the age group of 51-60 years, indicating that type 2 diabetes is more prevalent in the elderly, which is similar to that reported in other Indian studies [8]. In this study, the mean body mass index (BMI) of the study population was $25.58 \mathrm{~kg} / \mathrm{m}^{2}$, higher than the acceptable limits. A total of 30 patients (30\%) had a body mass index higher than $>25 \mathrm{~kg} / \mathrm{m}^{2}$. Of the 100 type 2 diabetic patients, 16 patients (12 females) had a body mass index of $>30 \mathrm{~kg} / \mathrm{m}^{2}$. The strong association between BMI and diabetes indicated that even minor BMI changes had adverse effects on the population. A similar study has been reported in the Indian population [9]. A total of $30 \%$ of patients had a family history of diabetes. Male patients had more cases of family history than females. A $51 \%$ of type 2 diabetic patients had a history of diabetes for 2-5 years, followed by $13 \%$ for $5-10$ years, $9 \%$ within 6 months, while $11 \%$ for 6 months -1 year, and $9 \%$ for $11-15$ years. New cases were only $6 \%$. It reflects that majority of the patients have long-standing diabetes mellitus. Our finding supports the report of risk factors for diabetic patients issued by the International diabetic federation [10]. Economic status indicates that middle-class people have more type 2 diabetic patients, which is reported in other Indian studies [11]. In the present study, antidiabetic drug prescribing patterns were analyzed from the prescriptions of all participants. Metformin was the most common drug prescribed as monotherapy and even as a part of combination therapy. These findings were similar to several other studies [12-14]. The American Diabetes Association (ADA) and European Association for the Study of Diabetes (EASD) guidelines also endorse metformin as the first-line drug for the treatment of T2DM. Metformin is associated with a shallow risk of hypoglycemia, does not cause weight gain rather may promote weight loss, has beneficial effects on lipid profile, and has a low cost $[15,16]$. Glimepiride metformin $1 \mathrm{mg} / 500 \mathrm{mg}$ combination therapy was the least prescribed, probably because of its efficacy; this finding supports other studies' evidence [17]. Sitagliptin is increasingly being prescribed in comparison to earlier studies, although as a part of combination therapy. Sitagliptin is linked with a low risk of hypoglycemia and other side effects than sulfonylureas as monotherapy and combination therapy with metformin $[16,18]$. The FBG data were not available for 27 patients. Of the 73 patients for whom the data were available during the study period, $58.9 \%$ of patients showed FBG levels higher than the acceptable limits. Postprandial (PP) blood glucose levels data were available for only 73 patients during the study period. A total 
Table 4: Fasting and postprandial blood glucose levels of participant subjects

\begin{tabular}{|c|c|c|c|c|c|c|c|c|c|}
\hline Total patients & Male & Female & FBG levels & $\%$ & Total patients & Male & Female & PP blood glucose levels & $\%$ \\
\hline 30 & 12 & 18 & $\leq 130 \mathrm{mmHg}$ & 41.09 & 20 & 8 & 12 & $<180$ mg\% & 27.39 \\
\hline 43 & 18 & 25 & $>130 \mathrm{mmHg}$ & 58.90 & 50 & 24 & 26 & $\geq 180 \mathrm{mg} \%$ & 68.49 \\
\hline 73 & & & Total & 100 & 73 & & & Total & \\
\hline 27 & & & Data not available & & 27 & & & Data not available & 27 \\
\hline
\end{tabular}

Table 5: Cost-effectiveness analysis of oral antidiabetic drugs

\begin{tabular}{lllll}
\hline Drug & $\begin{array}{l}\text { No. of } \\
\text { prescription }\end{array}$ & $\begin{array}{l}\text { Average total } \\
\text { direct cost (INR) }\end{array}$ & $\begin{array}{l}\text { The average decrease } \\
\text { in FBG (mg/d) }\end{array}$ & $\begin{array}{l}\text { ACER (Cost/unit } \\
\text { decrease in FBG) }\end{array}$ \\
\hline Metformin 500 mg & 21 & 766.9 & 24.05 & 31.88 \\
Metformin 850 mg & 6 & 650 & 27.92 & 23.28 \\
Glimepiride 4 mg & 10 & 900.7 & 34.69 & 25.96 \\
Glimepiride 1 mg+Metformin 500 mg & 2 & 690 & 32.66 & 21.12 \\
Glimepiride 2 mg+Metformin 500 mg & 8 & 560 & 35.78 & 15.65 \\
Sitagliptin 50 mg & 4 & 1960 & 31.04 & 63.14 \\
Sitagliptin+Metformin 50/500 & 8 & 950 & 31.04 & 30.60 \\
Sitagliptin+Metformin 50/850 & 6 & 940 & 31.04 & 30.28 \\
Vildagliptin & 4 & 700 & 22.5 & 31.11 \\
Vildagliptin+Metformin 50/850 & 8 & 650 & 21.01 & 30.93 \\
Vildagliptin+Metformin 50/500 & 7 & 650 & 20.03 & 32.45 \\
\hline
\end{tabular}

of $68.49 \%$ of whom had PP blood glucose levels higher than the normal limits. The higher values of the blood sugar levels reflect the patients' poor compliance with the therapy and the prescribed blood sugar testing, poor physical activity, and poor awareness about the cutoff points. This result was less than that reported internationally but higher than that reported in Indian studies [19]. Out of 100 T2DM, patient's data for glycated hemoglobin were available only for 45 patients. A total of $57.7 \%$ of patients showed HbA1c levels within the acceptable limits. Despite that HbA1c reflects the patient's metabolic control of the preceding 3 months and patient adherence, the HbA1c monitoring in type 2 diabetic patients is underutilized in this hospital setting. This may be attributed to the HbA1c test's high cost, low awareness, and lack of patient education [20]. CEA is one of the most applied forms of economic analysis in drug therapy. It helps to determine the cost variation between different therapies with similar outcomes in a particular therapeutic area. India being the diabetes capital of the world, plus the chronic nature of diabetes leads to the cost associated with the disease being extensive. The high cost of medications can influence the patient's compliance and damage his medical health and quality of life [21]. In this study, maximum reduction of FBG by an antidiabetic agent was seen with glimepiride $4 \mathrm{mg}$ ( $34.69 \mathrm{mg} / \mathrm{dl})$ and lowest with metformin $500 \mathrm{mg}$ $(24.05 \mathrm{mg} / \mathrm{dl})$. There are very few similar studies in the literature, and more are on oral antidiabetics [22]. Variation in average cost per unit reduction in FBG (ACER) of antidiabetes drug therapies prescribed (range from 9.95 to 63.14) was seen, like the variation seen in an earlier study by Acharya et al. Sulfonyl urea and biguanides combination were seen to be most cost effective [23]. The maximum expenditure was on antidiabetic agents (86.63\%), which also were seen in an earlier study by Grover et al. [24].

\section{CONCLUSION}

Most type 2 diabetic patients in the study population were treated with multiple oral antidiabetic therapies, as monotherapy metformin and sitagliptin were the most common choice. Due to various comorbidities in diabetic patients, the polypharmacy was more and to avoid irrational use of drugs and decrease polypharmacy, certain medicines which are not that essential according to patient condition (as multivitamins, analgesics, and antibiotics) can be avoided in prescription. The most commonly prescribed oral antidiabetic agent was metformin followed by glimepiride and glimepiride $2 \mathrm{mg}+$ metformin $500 \mathrm{mg}$ combination therapy. More than half of type 2 diabetic patients showed higher fasting and postprandial blood glucose levels than recommended. HbA1c monitoring was underutilized. Sulfonylurea gradually replaced by biguanides and that can be observed by prescribing patterns. CEA concludes that the cost associated with diabetes is enormous and varies greatly. The combination therapy of glimepiride $2 \mathrm{mg}+$ metformin $500 \mathrm{mg}$ was the most cost effective. The prescribing pattern should be carried out in a large population and at different locations in India so that the utilization patterns may be compared and later improved further.

\section{AUTHORS' CONTRIBUTIONS}

Ghadah Salim Mussttaf collected the data, patients follow-up, data organization, and wrote the paper. Dr. Anwar Habib designed the study, sample size determination, and designed the analysis. Marwan Mahtook collected and organized the data, performed the analysis, and paper writing and communication.

\section{CONFLICTS OF INTEREST}

We have no conflicts of interest to disclose.

\section{AUTHORS' FUNDING}

No funding.

\section{REFERENCES}

1. Khan MA, Hashim MJ, King JK, Govender RD, Mustafa H, Al Kaabi J. Epidemiology of Type 2 diabetes-global burden of disease and forecasted trends. J Epidemiol Glob Health 2020;10:107-111.

2. Brown MT, Bussell JK. Medication adherence: WHO cares? Mayo Clin Proc 2011;86:304-14.

3. Chaudhury A, Duvoor C, Dendi VS, Kraleti S, Chada A, Ravilla R, et al. Clinical review of antidiabetic drugs: Implications for Type 2 diabetes mellitus management. Front Endocrinol (Lausanne) 2017;8:6.

4. Tamilselvan T, Kumutha T, Lekshmi A, James A, Reji J, Cheriyan N. Pharmacoeconomical evaluation of oral hypoglycemic agents for Type-2 diabetes mellitus in a multispeciality hospital. Int J Pharm Sci Res 2017;8:2243-8.

5. Maiti R, Bhatia V, Padhy BM, Hota D. Essential medicines: An Indian perspective. Indian J Community Med 2015;40:223-32.

6. Bosworth HB, Granger BB, Mendys P, Brindis R, Burkholder R, Czajkowski SM, et al. Medication adherence: A call for action. Am Heart J 2011;162:412-24.

7. Pradeepa R, Mohan V. Changing scenario of the diabetes epidemic. Implications for India. Ind J Med Res 2002;116:121-32.

8. Jain A, Paranjape S. Prevalence of Type 2 diabetes mellitus in elderly in a primary care facility: An ideal facility. Indian J Endocrinol Metab 
2013;17:S318-22

9. Gupta S, Bansal S. Does a rise in BMI cause an increased risk of diabetes?: Evidence from India. PLoS One 2020;15:e0229716.

10. Wu Y, Ding Y, Tanaka Y, Zhang W. Risk factors contributing to Type 2 diabetes and recent advances in the treatment and prevention. Int $\mathrm{J}$ Med Sci 2014;11:1185-200

11. Chandra P, Gogate B, Gogate P, Thite N, Mutha A, Walimbe A. Economic burden of diabetes in urban Indians. Open Ophthalmol J 2014;8:91-4.

12. Lv Z, Guo Y. Metformin and its benefits for various diseases. Front Endocrinol (Lausanne) 2020;11:191

13. Alex SM, Sreelekshmi BS, Smitha S, Jiji KN, Menon AS, Devi UP. Drug utilization pattern of antidiabetic drugs among diabetic outpatients in a tertiary care hospital. Asian J Pharm Clin Res 2015;8:144-6.

14. Marín-Peñalver JJ, Martín-Timón I, Sevillano-Collantes C, Del Cañizo-Gómez FJ. Update on the treatment of Type 2 diabetes mellitus. World J Diabetes 2016;7:354-95.

15. Inzucchi SE, Bergenstal RM, Buse JB, Diamant M, Ferrannini E, Nauck M, et al. Management of hyperglycaemia in Type 2 diabetes: A patient-centered approach. Position statement of the American diabetes association (ADA) and the European association for the study of diabetes (EASD). Diabetologia 2012;55:1577-96.

16. American Diabetes Association. Approaches to glycemic treatment. Diab Care 2016;39:52-9.

17. Kim HS, Kim DM, Cha BS, Park TS, Kim KA, Kim DL, et al. efficacy of glimepiride/metformin fixed-dose combination vs metformin uptitration in Type 2 diabetic patients inadequately controlled on lowdose metformin monotherapy: A randomized, open label, parallel group, multicenter study in Korea. J Diabetes Investig 2014;5:701-8.
18. Arechavaleta R, Seck T, Chen Y, Krobot KJ, Neill EA, Duran L, et al. efficacy and safety of treatment with sitagliptin or glimepiride in patients with Type 2 diabetes inadequately controlled on metformin monotherapy: A randomized, double-blind, noninferiority trial. Diabetes Obes Metab 2011;13:160-8.

19. Colberg SR, Sigal RJ, Fernhall B, Regensteiner JG, Blissmer BJ, Rubin RR, et al. Exercise and Type 2 diabetes: The American college of sports medicine and the American diabetes association: Joint position statement. Diabetes Care 2010;33:e147-67.

20. Jafarian-Amirkhizi A, Sarayani A, Gholami K, Taghizadeh-Ghehi M, Heidari K, Jafarzadeh-Kohneloo A, et al. Adherence to medications, self-care activity, and HbAlc status among patients with Type 2 diabetes living in an urban area of Iran. J Diabetes Metab Disord 2018;17:165-72.

21. Abdelaziz MS, Rani HS, Ravindranath S, Shaik R, Kasim M, Salam AA. Pharmacoeconomic evaluation of oral-hypoglycemic agents at hospital in Bangalore. IOSR J Pharm Biol Sci 2015;10:46-50.

22. Basit A, Riaz M, Fawwad A. Glimepiride: Evidence-based facts, trends, and observations (GIFTS). Vasc Health Risk Manag 2012;8:463-72.

23. Acharya KG, Shah KN, Solanki ND, Rana DA. Evaluation of antidiabetic prescriptions, cost and adherence to treatment guidelines: A prospective, cross-sectional study at a tertiary care teaching hospital. J Basic Clin Pharma 2013;4:82-7.

24. Grover S, Avasthi A, Bhansali A, Chakrabarti S, Kulhara P. Cost of ambulatory care of diabetes mellitus: A study from north India. Postgrad Med J 2005;81:391-5. 